\title{
Gene Expression and Molecular Differences in Two Wheat Genotypes under Salt and Drought Stresses
}

\author{
Manal Hassan Eid \\ Botany Department, Faculty of Agriculture Suez Canal University, Ismailia, Egypt.
}

\begin{abstract}
$\mathbf{T}$ HIS STUDY was conducted to point out some highlights on the difference between two contrasting tolerant wheat varieties regarding to genetic expression and molecular characterization under salt and drought stress. Two different tolerant wheat genotypes namely, Gemmiza9 (sensitive) and Sakha93 (tolerant) were used to investigate the molecular and genetic differences under salt and drought stress. Stress treatments were used $\mathrm{NaCl}$ and poly ethylene glycol (PEG) of different levels. Sodium dodecyl sulphate polyacrylamide gel electrophoresis(SDS PAGE) analysis was revealed three disappeared bands with 15, 25, 90 kilodalton (KD) in salt treated plants of Gemmiza9 and appeared these bands as constant in controlled and salt treated plants of Sakha93. Contradict vision for protein profile was under drought stress that constant bands were disappeared and new synthetic bands were exhibited in both Gemmiza9 and Sakha93. Moreover, Random amplification of polymorphic DNA (RAPD) markers were produced several number of unique bands in Sakha93. Primer 2 generated unique bands in Gemmiza9. Simple sequence repeats (SSR) markers were 100\% polymorphism. WMC_179 marker out of six markers was present unique alleles only in Sakha93. This marker might be practical and advantageous to the genotype that recognized to tolerance QTL markers alleles to utilize in marker assisted selection in further study. Comparison between RAPD and SSR markers was revealed that QND was less (0.06) in RAPD than in SSR (0.56). EMI was higher (0.31) in RAPD than in SSR (0.23). Nonetheless, the findings might be valuable and helpful to identify the genetic and molecular characterizations of different tolerant genotypes.
\end{abstract}

Keywords: Drought stress, Genotype, Protein profile, Salinity, Wheat.

\section{Introduction}

In semi arid to arid regions, salt and drought stresses are considered the most environmental abiotic stresses on crop productivity reduction. Salt and drought stresses have a lot of destructive effects on plants which are physiologically similar to each other (Sharbatkhari et al., 2013). Upon exposure to abiotic stress conditions, plants undergo a variety of changes from physiological adaptation to gene expression (Flowers et al., 2015).

Several studies have addressed cross-talk between drought and salt stresses (Abdul Kader \& Lindberg, 2010 and Khalili et al., 2018). Salt interferes with plant growth and can lead to physiological drought and ionic toxicity. Thus, salinity and drought stresses often affects the physiological aspects of plant metabolism, creating tension (hyper -ionic and hyper osmotic) and eventually plant death. Salinity and drought stresses overlap on the physiological level because salt in soil decreases the amount of available water and leads to reduced water absorption (Sewelam et al., 2016). The tolerance to salt stress is accompanied by alterations in the levels of proteins. Salinity causes either a decrease or increase in the level of soluble proteins or the complete disappearance some proteins when compared to the control treatment. In addition, salt stress promotes a complete loss of present proteins and the synthesis of newly formed proteins (Ashrafi \& Shaban, 2014). Drought tolerance trait is related to protein expression. Some proteins are produced by plant only under drought stress condition and are called drought induced proteins. Others proteins that are always present in tissues and are not affected due to drought are called constitutive proteins. The major of research on drought tolerance related to proteins is focused on induced proteins (Parchin et al., 2014 and Ullah et al., 2014). 
Exploring the tolerance mechanisms in wheat is essential to provide more information about the molecular and genetic principles of tolerance that facilitate the development and improvement in breeding of tolerant genotypes. One of several approaches to understand tolerance mechanisms are protein profile of plants under stress conditions. Biochemical techniques like Sodium dodecyl sulphate polyacrylamide gel electrophoresis (SDSPAGE) that is a cheap, easy and widely practical method for displaying protein profiles of plants under different conditions (Razavizadeh, 2015 and Abdelhaliem \& Al-Huqail, 2016). Moreover, applying molecular-genetic tools promotes to emergent new approaches in classification of different tolerant genotypes. The random amplified polymorphic DNA (RAPD) marker procedure is simple and rapid, it does not require previous sequence information, and usually amplified numerous genetic loci (Akash, 2013). Simple sequence repeat (SSR) is high due to co-dominant nature, chromosome-specific, reproducibility and has great efficiency of polymorphism and high information content to detect precisely the genetic differences among various genotypes $\left(\mathrm{O}^{\prime}\right.$ zlem et al., 2018 and Piyusha \& Naveen, 2018). However, biochemical and molecular markers have been applied to characterize cultivars independent of plant tissue or environmental effect and cultivar identification at very early stage of plant development under stress conditions (Manifesto et al., 2001 and Tomar et al., 2016).

Obviously, wheat is considered as an outstanding model to explore salt/drought tolerance although its genetic complexity (Dashtpagerdi et al. 2018). Lately, the achievement of chromosome-based draft sequencing of hexaploid bread wheat genome will speed wheat breeding and discovery of key genes controlling complex traits in response to salt/ drought (IWGSC, 2014). Depended on the wheat genome sequencing data, a lot of investigations attempt to isolate and employ mechanisms adopted by wheat to overcome salt/drought stress.

Amis of this study are to: 1- Explore the differences in protein expression in controlled and stress treated plants, 2- Investigate the difference in protein profile between salt stress and drought stress, 3- Detect the genetic and molecular different between two contrasting wheat genotypes under salt and drought stresses using RAPD and SSR techniques and 4-Compare the efficiency of RAPD and SSR markers.

\section{Material and Methods}

\section{Plant material}

Two Egyptian wheat varieties (Triticum aestivum L.): Gemmiza9 (sensitive) and Sakha93 (tolerant) were obtained from Field Crops Research Institute, Egypt were used.

\section{Experimental details}

This study was performed under green house conditions at the experimental Farm of Faculty of Agriculture, Ismailia Egypt during 2016/2017. The experiment was carried out in randomized block design with three replicates. The pots of each cultivar were separated into two groups, one was subjected to drought stress and the other was to salt stress. Plastic pots $(25 \mathrm{~cm}$ diameter) were filled a combination of sandy soil and peat moss $(1: 1, \mathrm{v}$ : v). Ten seeds of each cultivar were sowed per pot and watered two times weekly. Plants were thinned to five per pot after one week from the sowing date.

\section{Stress procedures applied}

Three weeks later the sowing date, the plants were subjected to stress for two weeks. Drought stress was created by preparing $20 \%$ and $30 \%$ of poly ethylene glycol (PEG-6000) concentrations as described by Michel \& Kaufmann (1973).

Salt stress was applied by the addition of 150 and $200 \mathrm{mM} \mathrm{NaCl}$ to irrigation water. While a tap water irrigation was considered as a control treatment.

\section{SDS-PAGE analysis}

Three plants were sampled for each genotype and each treatment. Of leaf, $0.5 \mathrm{~g}$ was taken and gridding in a cold pestle mortar with liquid nitrogen and mixed with $2 \mathrm{ml}$ extraction buffer containing $1 \mathrm{M}$ Tris $\mathrm{HCl}, \mathrm{pH} 8.0,250 \mathrm{mM} \mathrm{NaCl}$, $0.25 \mathrm{mM}$ EDTA, $0.5 \%(\mathrm{w} / \mathrm{v})$ SDS and $10 \mathrm{mM} \mathrm{b}$ mercaptoethanol. The sample was then vortexed and centrifuged at $13,000 \mathrm{rpm}$ for $10 \mathrm{~min}$ under cooling. The supernatants were collected and considered as leaf protein extracts. Protein concentration was determined by absorbance at $595 \mathrm{~nm}$ using a spectrophotometer and expressed as $\mu \mathrm{g} \mathrm{g}^{-1}$ fresh weight (Bradford, 1976).

The supernatants were fractionated by $10 \%$ SDS-PAGE (Laemmili, 1970); running and staining were standard procedures. Electrophorogram for each variety were scored. 
Molecular analysis

DNA extraction

The basic DNA extraction protocol using the CTAB (cetylhexadecyl-trimethyl ammonium bromide) method as described by Dellaporta et al. (1983) was used with slight modifications by Porebski et al. (1997), for obtaining good quality total DNA.

\section{RAPD-PCR protocol}

RAPD analysis was performed according to Williams et al. (1990), with 6 primers were selected from Operon Technology, USA (Table 1). DNA from each cultivar used to amplify with universal primer each contain in a volume of (final concentration) dNTPs (10mM),PCR assay buffer (10X), Mgcl2 (25mM), primers (5p mol), Taq DNA polymerase (3U/ $\mu \mathrm{l})$, DNA (60ng) and sterile water to make the volume.

\section{SSR-PCR protocol}

Six SSR markers (Table 1) were selected were previously described by Gupta et al. (2003). The PCR reaction mixture $(25 \mu 1$ total) consisted of $50 \mathrm{mM} \mathrm{KCl}$ and $10 \mathrm{mM}$ Tris- $\mathrm{HCl}(\mathrm{pH} 8.8), 2 \mathrm{mM}$ $\mathrm{MgCl} 2,125 \mathrm{mM}$ of $\mathrm{dNTP}$, 50ng of each primer, 1.0 unit of Taq polymerase and $20 \mathrm{ng}$ of genomic DNA. PCR products were separated on $2 \%$ agarose gel and stained with ethidium bromide to check the PCR amplification and determine approximately the size of the amplified fragments.

\section{Scoring data and analysis}

RAPD and SSR bands were scored visually on the basis of their presence (1) or absence (0), separately for each cultivar of wheat. The scores obtained using all polymorphic markers were then calculated for number of alleles, effective number of allele, Power Marker version 3.25 was used to determine the polymorphism information content (PIC), Efficiency of polymorphism detection as the Marker index (MI) and Effective multiplex ratio (E), defined by Powell et al. (1996). The qualitative nature of data (QND) and the effective marker index (EMI) were estimated as described by Varshney et al. (2007).

\section{Results and Discussion}

\section{Gene expression}

The protein profile was constructed on base of SDS PAGE analysis, considering that the revealed protein alterations quantitatively in plants under different environmental stresses. The protein profile under salt stress ranged from 8 to 129 kilodalton (Table 2). Gemmiza9 was displayed 24 bands for controlled plants and 21 bands for both salt treated plants. Sakha93 was recorded 24 bands for control and 26 bands for both salt treated plants. The variation was observed in number of bands between the controlled and treaded plants may be attributed to alternation in DNA-nitrogenous bases, in protein sites or amino acid sequences, or frameshift mutations. Therefore, the number of different polypeptide bands arising from protein synthesis (alternative splicing and/or posttranscription modification) is significantly greater than the number of genes in a genome, thus it can be considered as markers of these genes (Mondini et al., 2009).

TABLE 1. Codes and sequence for 6 RAPD and 6 SSR primers.

\begin{tabular}{|c|c|c|c|c|}
\hline \multirow{2}{*}{ Number } & \multicolumn{2}{|c|}{ RAPD primer } & \multicolumn{2}{|r|}{ SSR primer } \\
\hline & Marker code & Sequences $\left(5^{\prime}-3^{\prime}\right)$ & Marker code & Sequences $\left(5^{\prime}-3^{\prime}\right)$ \\
\hline 1 & OPQ-14 & $5^{5} \mathrm{GGACGCTTCA}^{-3}$ & Wms 108 & $\begin{array}{c}\text { F: }^{5} \text { ATT AAT ACC TGA GGG AGG TGC- }{ }^{3} \\
\text { R: GGT CTC AGG AGC AAG AAC AC }\end{array}$ \\
\hline 2 & OPM-05 & 5'- GGGAACGTGT -3’ & Wms 118 & $\begin{array}{c}\text { F: }{ }^{5-} \text { GAT GGT GCC ACT TGA GCA TG- }{ }^{3} \\
\text { R:GAT TG TCA AAT GGA ACA CCC }\end{array}$ \\
\hline 3 & OPA-03 & 5'-AGTCAGCCAC-3' & Wmc121 & $\begin{array}{l}\text { F:5-GGCTGTGGTCTCCCGATCATTC }{ }^{-3} \\
\text { R:ACTGGACTTGAGGAGGCTGGCA }\end{array}$ \\
\hline 4 & OP-A07 & 5'-GTAACCAGCC-3' & Wmc179 & $\begin{array}{c}\text { F: }{ }^{5-C A T G G T G G C C A T G A G T G G A G G T}{ }^{-3} \\
\text { R:CATGATCTTGCGTGTGCGTAGG }\end{array}$ \\
\hline 5 & OP-A09 & 5'-GGGTAACGCC-3’' & Wmc463 & $\begin{array}{c}\text { F:5-GATTGTATAGTCGGTTACCCCT }^{-3} \\
\text { R:ATTAGTGCCCTCCATAATTGTG }\end{array}$ \\
\hline 6 & OP-A11 & 5'- CAATCGCCGT'-3' & Wmc488 & $\begin{array}{c}\text { F: }: 5-A A A G C A C A A C C A G T T A T G C C A C-3 \\
\text { R:GAACCATA GTCACATATCACGA }\end{array}$ \\
\hline
\end{tabular}


TABLE 2. SDS-PAGE polypeptide banding pattern of the protein under salt stress.

\begin{tabular}{|c|c|c|c|c|c|c|c|}
\hline No. & $\begin{array}{c}\text { Marker } \\
\text { MW }\end{array}$ & G9/C & $150 \mathrm{mM}$ & $200 \mathrm{mM}$ & Sakha93/C & $150 \mathrm{mM}$ & $200 \mathrm{mM}$ \\
\hline 1 & 129 & + & + & + & + & + & + \\
\hline 2 & 123 & + & + & + & + & + & + \\
\hline 3 & 117 & + & + & + & + & + & + \\
\hline 4 & 108 & + & + & + & + & + & + \\
\hline 5 & 102 & + & + & + & + & + & + \\
\hline 6 & 99 & + & + & + & + & + & + \\
\hline 7 & 94 & + & + & + & + & + & + \\
\hline 8 & 90 & + & - & - & + & + & + \\
\hline 9 & 87 & + & + & + & + & + & + \\
\hline 10 & 80 & + & + & + & + & + & + \\
\hline 11 & 63 & + & + & + & + & + & + \\
\hline 12 & 57 & + & + & + & + & + & + \\
\hline 13 & 55 & - & - & - & - & + & + \\
\hline 14 & 45 & + & + & + & + & + & + \\
\hline 15 & 39 & + & + & + & + & + & + \\
\hline 16 & 30 & + & + & + & + & + & + \\
\hline 17 & 28 & + & + & + & + & + & + \\
\hline 18 & 25 & + & - & - & + & + & + \\
\hline 19 & 26 & + & + & + & + & + & + \\
\hline 20 & 25 & + & + & + & + & + & + \\
\hline 21 & 23 & + & + & + & + & + & + \\
\hline 22 & 20 & + & + & + & + & + & + \\
\hline 23 & 15 & + & - & - & + & + & + \\
\hline 24 & 12 & + & + & + & + & + & + \\
\hline 25 & 10 & + & + & + & + & + & + \\
\hline 26 & 8 & - & - & - & - & + & + \\
\hline Total bands & & 24 & 21 & 21 & 24 & 26 & 26 \\
\hline
\end{tabular}

*MW: Molecular weight.

Moreover, Gemmiza9 presented three bands out of 24 bands in controlled plants that were not obtained in both salt treated plants. These disappeared bands with $15,25,90 \mathrm{kD}$ might be due to denatured or not expressed in salt treated plants. Theoretically, disappearance of the proteins may be interpreted as the "turning off" of protein synthetic genetic machinery (genes) in response to salt treatment or may be due to the breaking of a small number of peptide bonds, consequential in the construction of shorter polypeptide chains than possessed by the original protein, caused by the missing of DNA sequences or removal of the related genes. Other assumption may be due to the gathering or cross linking of individual polypeptide chains resulting in protein denaturation (Elavumoottil et al., 2003 and Shikazono et al., 2005). Numerous studies were found salt stress was accelerated the degradation of plants as well as suppressed protein synthesis (Maleki et al., 2014 and Wu et al., 2018).
Other 21 bands were maintained in both salt treated plants of Gemmiza9 presenting similar molecular weights to controlled plants. They could be genetically related to germination and growth processes of plants (Rani et al., 2007). Interestingly, Sakha93 was displayed the same three bands with 15,25 and $90 \mathrm{kD}$ in control and in salt treated plants. At this point, salt stress protein expression could cause by the genetic basis of tolerant genotype and the ability of genotype for adapting to stress (Husaini \& Rafiqi, 2012).

Regarding to Sakha93, two new bands with molecular weight 8 and 55kD were exhibited only in salt treated plants and they were not obtained in controlled plants (Table 2). Understandingly, one of many symptoms of salinity stress is the inhibition of regular protein synthesis, while contributing factors of salinity tolerance is de novo synthesis of stress related proteins (Folgado et al., 2013 and Karam 
et al., 2016). Consequently, new bands of Sakha93 might have an impact on osmotic adjustment avoidance the dehydration damage opposing salt stress (Trivedi \& Patel, 2016). For that reason, two new bands could consider biochemical markers of the sensitivity of the concerned cultivar for species toward salt stress.

Protein profiles under drought stress were ranged from 9 to $151 \mathrm{kD}$ and revealed various numbers of bands regarding to non-treated and stress treated plants as well as the two varieties (Table 3). Many new bands with different molecular weights were synthesized under drought stress in Gemmiza9. The reason might be attributed to some drought responsive genes expressing in sensitive genotype as well as in tolerant genotype, they might not response for tolerant drought (Guo et al., 2018). On other hand, many constant bands were in controlled plants that they disappeared in stress treated plants.

TABLE 3. SDS-PAGE polypeptide banding pattern of the protein under drought stress.

\begin{tabular}{|c|c|c|c|c|c|c|c|}
\hline No. & MW & G9/C & $20 \%$ PEG & $30 \%$ PEG & Sakha93/C & $20 \%$ PEG & $30 \%$ PEG \\
\hline 1 & 151 & - & - & - & - & + & + \\
\hline 2 & 133 & + & + & + & + & + & + \\
\hline 3 & 127 & + & + & + & + & + & + \\
\hline 4 & 121 & - & + & + & - & + & + \\
\hline 5 & 120 & - & - & - & - & - & + \\
\hline 6 & 106 & + & - & + & + & + & + \\
\hline 7 & 95 & - & - & - & + & - & + \\
\hline 8 & 93 & - & - & - & + & + & - \\
\hline 9 & 76 & + & + & + & + & + & + \\
\hline 10 & 74 & - & - & - & + & + & \\
\hline 11 & 70 & + & - & + & + & + & + \\
\hline 12 & 68 & + & + & - & + & + & - \\
\hline 13 & 63 & - & - & - & - & + & + \\
\hline 14 & 61 & + & - & - & - & - & - \\
\hline 15 & 59 & - & - & + & + & + & + \\
\hline 16 & 57 & + & + & + & + & + & + \\
\hline 17 & 56 & + & + & - & + & + & - \\
\hline 18 & 55 & - & - & - & - & - & + \\
\hline 19 & 54 & - & - & + & - & - & - \\
\hline 20 & 50 & + & + & + & + & + & + \\
\hline 21 & 49 & - & + & - & + & + & + \\
\hline 22 & 45 & - & - & - & - & + & + \\
\hline 23 & 42 & - & + & - & - & - & - \\
\hline 24 & 34 & + & - & - & - & - & - \\
\hline 25 & 30 & + & + & + & + & + & + \\
\hline 26 & 27 & - & + & + & - & - & + \\
\hline 27 & 26 & + & - & - & + & + & - \\
\hline 28 & 25 & + & + & + & + & + & + \\
\hline 29 & 17 & + & + & + & + & + & + \\
\hline 30 & 10 & - & - & - & + & + & - \\
\hline 31 & 9 & + & + & + & + & + & + \\
\hline Total bands & & 16 & 15 & 15 & 20 & 23 & 21 \\
\hline
\end{tabular}

*MW: Molecular weight. 
Similar trend in Sakha93, many new bands were appeared in stress treated plants. On other hand, several constant bands were in control that not obtained in stress treated plants. The explanation is that drought stress might change plant gene expression and direct particular genes that increase their transcripts and consequently enhance the corresponded proteins. Reflecting on the new bands emergence and other constant bands denatured or not express at this level of stress (Khalili et al., 2018). Otherwise, the new bands were existed in different tolerant genotypes under drought stress by increasing protein content at the outflow amino acid that influenced these compounds inter an alteration (EL-Hadary et al., 2018). The results are in line with those obtained by Kamal et al. (2010) and Moradpour et al. (2014). Controversy, Ashrafi \& Shaban (2014) concluded that drought impose no adverse effect on the protein profile of wheat genotypes. Due to SDS-PAGE analysis might be incapable to identify the variations among wheat genotypes in their case.

Noticeably, the protein profile under salt stress was differently from the case under drought stress. Table 2 showed that few numbers of constant bands were disappeared in salt treated plants for the sensitive genotype. Few numbers of newly synthesized bands were presented only in salt stress treated plants of the tolerant genotype. Contrasting, constant bands disappeared and newly synthesized bands were displayed in both sensitive and tolerant genotypes under drought stress (Table 3 ).

The explanation for these observations may be attributed to the following:

1- The expression of transcription factor genes might not be influenced by genotyping, rather they depend on the physiological responses of the genotype under drought stress. This assumption was supported by findings of Dashtpagerdi et al. (2018). Therefore, tolerant genotypes might enhance the tolerance under drought stress by protection, achieving through other cellular process such as the proteins structural and functional and stomata adjustment (Guo et al., 2018).

2- Salt tolerance and drought tolerance might be regulated differently by various genes. Such as number genes of the dehydrin (DHN) gene family were expressed only in stress treated plants, validating the function of these proteins in the molecular mechanisms activated by plants in response to drought stress. Thus the expression profiles were different for each gene analyzed (Huseynova et al., 2015).

3- The early seedling growth is the most sensitive stage to salt stress; a $\mathrm{NaCl}$ has toxic effects containing changes in the ion balance and elevated $\mathrm{Na}^{+}$concentrations in the cytoplasm (Shavrukov, 2013 and Terletskaya et al., 2017). Salt stress might suppress the constant bands and prevent new synthesis of bands in treated plants of sensitive genotypes. Even drought stress has much higher effect in the reproductive phase compared to the vegetative phase. So that the treated plants of sensitive genotype might have more ability to respond and regulate drought stress than tolerant genotypes at seedling stages. This opinion was proved in work of Guo et al. (2018) who observed that several metabolites displayed a similar alteration in response to drought stress in wheat sensitive and tolerant seedling.

4- Nonetheless, the new bands were obtained in drought treated plants of sensitive genotype (Gemmiza9). Since new band intensities were relatively weak; therefore, they might not be the only base for drought tolerance and provide no efficiently protection against drought stress as those of tolerant genotype (Sakha93). Similar suggestion was in work of Bowne et al. (2012) provide molecular proof for the cultivar-specific differences in wheat different tolerant cultivars under drought stress.

For recognizing and demonstrating which, assumption is an accurate and an efficient or the entire assumptions are practical and reasonable, the present study regained further investigation to detect which genes are involved in molecular mechanism and determine their role. Nowadays, microarray analysis can supply significant information for recognition and bio-imagination of gene expression pattern.

\section{Molecular characterization}

Six RAPD markers produced 90 bands, ranging from 10 to 23 with average 15 bands. Because of RAPD markers have distinguishing of binding sites over the entire genome of the genotypes used, give this high variation in the number of bands (Preety et al., 2010). Nevertheless, stress tolerance is a complex character that influenced by environmental factors and also character is 
non-Mendelian inheritance ruled by many genetic loci. Sakha93 was displayed 27 bands out of 35 polymorphic bands $(77 \%)$ which are genotypespecific, i.e. not present in other genotypes. Thus, it proposes the existence of a definite gene locus in $77 \%$ of polymorphism that might be linked with stress tolerance (Huseynova et al., 2015). Because of RAPD markers link randomly to the sequences that different bands were amplified by numerous of different sequences. Consequently, these bands were extremely precise to classify the genotype. These unique bands might relate to stress tolerance in Sakha93. In addition, they may be utilized to apply in further investigations as practical markers to distinguish tolerant genotypes or convert to SCAR (sequence characterized amplified regions) markers to identify tolerant genes and use for large scale stress tolerance screening of genotypes. On other hand, six RAPD markers were generated 27 monomorphic bands and were conserved in both genotypes. Nevertheless, RAPD markers are dominant that complicate to know a locus is heterozygous or homozygous. But the bands of same size amplified with same marker were believed that they were at the same locus, comprising two identical alleles in wheat genotypes. Consequently, RAPD dominant markers are not problems in this finding because of wheat is self-pollinating.

Whereas, OPM-05 marker was produced three polymorphic bands, 500, 260, 200pb and they were present only in Gemmiza9. Thus, OPM-05 marker might not consider completely appropriate to tolerant genotype. Note worthy is that many authors published numerous studies for utilizing RAPD markers to detect the salt and drought tolerant genotypes (Kanawapee et al., 2011, Islam et al., 2013 and Damor et al., 2016). However, this study evidenced that the two genotypes were differentiated using RAPD markers. Therefore, the two genotypes are recommended as parents to involve in hybridization program that construct QTL (quantitative trait locus) of stress tolerance.

With respect to six SSR markers, five markers were found polymorphic and discarded Wms118 marker. This excluded maker produced smear bands with an unclear major product size. Although this marker succeeds in amplifying in some wheat genotypes while fails in other genotypes. In this investigation, it might be that the corresponding microsatellite sites are distantly located in wheat DNA in such a way that no amplification occurred. However, five SSR markers revealed ten alleles with average of 2 per locus. The low number of alleles of five SSR reflected the low possibility to detect tolerance genes in the genotypes used (Kanawapee et al., 2011). However, the low number of bands might due to the quality of figurative agarose used to split the amplified products or the exclusion of the monomorphic and spurious bands from analysis, reducing the number of alleles (Shah et al., 2013). Other explanations might be due to the result by the 'short allele dominance', where, in heterozygotes including a short and a long allele, only the short allele is sufficiently amplified in the PCR reaction (Wattier et al.,1998).

On other hand, Wmc179 marker was present as unique alleles only in Sakha93. This marker might be practical and advantageous to the genotype recognized to tolerance QTL markers alleles to utilize in marker assisted selection but it might be needed extra investigation by advanced techniques (Fatima et al., 2018). Moreover, in previous work of Chen et al. (2012) revealed Wmc179 was amplified unique alleles relating to stripe rust in wheat.

Table 4 was showed that the average of Effective number of alleles was lower (9.52 and 1.6) than observed number of alleles (15 and 2) for RAPD and SSR, respectively. Because of low frequencies alleles had little contribution to the effective number of alleles.

RAPD markers showed the highest value of PIC in the examined genotypes with an average of 0.89 . While SSR markers showed the lowest value as an average of PIC values calculated 0.38 . However, the PIC depended on the number of alleles detected and on their distribution frequency (Botstein et al., 1980). Also, PIC was influenced by location of primers in the genome used for study and genotype sensitivity to method used (Pachauri et al., 2013).

Despite the fact that wheat is widely self crossing, SSR markers were recorded 100\% polymorphism. This finding was in constant with O"zlem et al (2018) and Piyusha \& Naveen (2018). Expectably, SSR markers were detected 100\% polymorphism as a consequence of replication slippage (Powell et al., 1996) or it might due to SSR markers that investigated for polymorphism among a set of genotypes (Fatima et al., 2018). 
TABLE 4. Molecular characteristics of the 6 RAPD and 5 SSR primers.

\begin{tabular}{llcc}
\hline No. & \multicolumn{1}{c}{ Indexes } & RAPD & SSR \\
\hline 1 & Number of markers /primers & 6 & 5 \\
2 & number of polymorphic bands & 35 & 10 \\
3 & Average number of polymorphic bands /primer & 5.83 & 2 \\
4 & Number of non-polymorphic & 55 & 0 \\
5 & Number of loci & 90 & 5 \\
6 & Number of loci /marker & 15 & 1 \\
7 & Effective number of alleles & 9.52 & 1.6 \\
8 & Average of Polymorphic information content (PIC) & 0.89 & 0.38 \\
9 & Fraction of polymorphism & 0.39 & 1 \\
10 & Effective multi ratio (E) & 5.85 & 1 \\
11 & Marker index (MI) & 5.21 & 0.38 \\
12 & qualitative nature of data (QND) & 0.06 & 0.6 \\
13 & Effective Marker index (EMI) & 0.31 & 0.23 \\
\hline
\end{tabular}

Actually, each RAPD marker represent various genomic regions simultaneously and amplified huge number of fragments in one lane of gel and then the effective multiplex ratio was high (5.85) in RAPD markers. Each SSR marker presented one specific locus that the average loci of five SSR was 1.0. Consequently, the effective multiplex ratio was equal to 1.0 in SSR markers (Baraket et al., 2010).

RAPD had higher MI (5.21) than SSR (0.38). Because of MI depended more on effective multiplex ratio and the number of bands than on the ratio of polymorphism detected (Powell et al., 1996). In case of RAPD, the six markers showed a low level of polymorphism compared to SSR markers but they had average of $E$ was high (5.85) and average number of loci per marker was 15. Since, each RAPD marker represented various genomic regions simultaneously and amplified huge number of fragments in one lane of gel, and then E was high. Although five SSR markers recorded $100 \%$ polymorphism but MI was low attributing to lower the E and the lower number of bands. Since, Each SSR marker presented one specific locus that the average loci of five SSR was 1.0. Consequently, the effective multiplex ratio was equal to 1.0 in SSR markers (Baraket et al., 2010).

The QND was less (0.06) in RAPD than in SSR (0.56). The explanation might be RAPD was difficult to ascribe the multi-locus gel where SSR was simple to evaluate (Varshney et al., 2007). EMI was recorded for 0.31 for RAPD whereas 0.23 for SSR. However, EMI covered the information of the data quality, fraction of polymorphic fragments and multiplex ratio for each molecular analysis.

However, both RAPD and SSR markers were amplified DNA and identified the differences between two contrast wheat genotypes. Each set of marker was achieved various number of unique alleles. SSR markers were able to detect high percentage of polymorphism in two wheat genotypes, with considering the narrow genetic diversity in wheat.

\section{Conclusion}

This study was conducted to point out some highlights on the difference between two contrasting tolerant wheat genotypes regarding genetic expression and molecular characterization under salt and drought stress. SDS PAGE analysis was used as a simple and easy method to detect the protein profile for each genotype under salt/ drought stress. Even though the protein profile was not approved as a stable marker because it is influenced by different treatments, it was sufficient to detect variation between the two genotypes and between the different stress treatments. It can be utilized as a biochemical marker to give platform for more investigation on understanding the cellular mechanisms that involve in salt/drought tolerance. With respect to RAPD and SSR molecular markers, they were used to identify and distinguish the different fingerings between the two genotypes. Findings were revealed high ratio of polymorphism and few numbers of unique alleles for each genotype. Consequently, RAPD and SSR molecular markers were able to identify and classify each genotype 
individually. Moreover, the study was hinged on two genotypes and was not taken as fixed standards but it was successful to make a good comparison between the RAPD and SSR markers. Even all DNA templates were amplified by RAPD and SSR markers. Both methods exhibited different appearances of genetic discriminations, since RAPD markers selected amplified part of DNA sequences of unknown function and based randomly on genome, SSR defined specific sites on genome. Concerning, induce stresses and response of contrasting tolerant genotypes were evaluated under green house conditions that define the sensitive/tolerant genotypes should be examined in field to verify their responsiveness to stress from morphological and physiological aspects at large scale in the future. Nonetheless, the findings might be useful to recognize the genetic and molecular characterizations of different tolerant genotypes.

\section{References}

Abdelhaliem, E. and Al-Huqail, A. (2016) Detection of protein and DNA damage induced by elevated carbon dioxide and ozone in Triticum aestivum $\mathrm{L}$. using biomarker and comet assay. Genetics and Molecular Research, 15(2), 1-19.

Abdul Kader, M.D. and Lindberg, S. (2010) Cytosolic calcium and $\mathrm{pH}$ signaling in plants under salinity stress. Plant Signaling and Behavior, 5, 233-238.

Akash, M. (2013) Development of SCAR markers for molecular tagging of drought tolerance QTL in barley. Life Sci. J. 10(12s).

Ashrafi, R. and Shaban, M. (2014) Effect of water deficit on total protein and protein profile in wheat (Triticum aestivum L.) genotypes. Int. J. Adv. Biol. Biom. Res. 2(2), 328-331

Baraket, G., Chatti, K., Saddoud, O. and Hannachi, A.S. (2010) Comparative assessment of SSR and AFLP markers for evaluation of genetic diversity and conservation of fig, Ficus carica L., genetic resources in Tunisia. Plant Mol. Biol. Rep. 29, 171184.

Botstein, D., White, R., Skalnik, M. and Davies, R. (1980) Construction of a genetic linkage map in man using restriction fragment length polymorphism. Am. J. Hum.Genet. 32, 314-331.
Bowne, J.B., Tim, A., Erwina, J.J., Thorsten S. and Peter, L. (2012) Drought responses of leaf tissues from wheat cultivars of differing drought tolerance at the metabolite level. Molecular Plant, 5(2), 418429.

Bradford, M.M. (1976) A rapid and sensitive method for the quantification of microgram quantities of proteins utilizing the principle of protein dye binding. Anal. Biochem. 72, 248-254.

Chen, J., Chenggen, C., Edward, J., Mary, J., Xianming, C. and Steven, X. (2012) Genome-wide identification of QTL conferring high-temperature adult-plant (HTAP) resistance to stripe rust (Puccinia striiformis f. sp. tritici) in wheat. Molecular Breeding, 29, 791-800.

Damor, P.R., Narwade, A.V., Jadav, S.K. and Viradiya, Y.A. (2016) Molecular characterization of six pigeonpea varieties for drought tolerance by using RAPD markers. IJAEB, 9(5), 725-730.

Dashtpagerdi, R., Esmaeil, E. and Ali, N. (2018) Molecular characterization of Brassica napus stress related transcription factors, BnMYB44 and $B n V I P 1$, selected based on comparative analysis of Arabidopsis thaliana and Eutrema salsugineum transcriptomes. Molecular Biology Reports, 45, 1111-1124

Dellaporta, S.L., Wood, J. and Hicks, J.B. (1983) A plant DNA minipreparation: Version II. Plant Molecular Biology Reporter, 1(4). pp. 19-21. ISSN 07359640 (ISSN).

Elavumoottil, O.C., Martin, J.P. and Moreno, M.L. (2003) Changes in sugars, sucrose synthase activity andproteins in salinity tolerance callus and cell suspension cultures of Brassica oleracea L. Biol. Plant. 46, 7-12.

EL-Hadary, Mona H., EL-Sherbini, Shimaa S. and Omar, Samar A. (2018) Molecular characterization and response of five soybean genotypes to PEG Treatment. Egypt. J. Genet. Cytol. 47, 175-192.

Fatima, S., Chaudhari, K., Akhtar, S. and Amjad, M. (2018) Mapping QTLs for yield and yield components under drought stress in bread wheat (Triticum aestivum L.). Applied Ecology and Environmental Research, 16(4), 4431-4453.

Flowers, T., Munns, R. and Colmer, T. (2015) Sodium 
chloride toxicity and the cellular basis of salt tolerance in halophytes. Annals of Botany, 115, 419-431.

Folgado, R., Kjell, S. and Jean-Francois, H. (2013) Differential protein expression in response to abiotic stress in two potato species: Solanum commersonii Dun and Solanum tuberosum L. Int. J. Mol. Sci. 14(3), 4912-4933. Doi: 10.3390/ ijms 14034912

Guo, R., Lian, X., Feng, X., Qi, L. and Hao, R. (2018) Metabolic responses to drought stress in the tissues of drought-tolerant and drought-sensitive wheat genotype seedlings. AoB PLANTS, 10(1), 1-13.

Gupta, P.K., Rustgi, S., Sharma, S., Singh, R., Kumar, N. and Balyan, H.S. (2003) Transferable EST-SSR markers for the study of polymorphism and genetic diversity in bread wheat. Mol. Genet. Genom. 270, 315-323

Husaini, A. and Matteen, R. (2012) Role of osmotin in strawberry improvement. Plant Mol. Biol. Rep. 30, 1055-1064

Huseynova, M., Rustamova, S.M., Nasrullayeva, M.Y. and Aliyev, J.A. (2015) Screening of barley genotypes for drought tolerance using molecular markers. International Journal of Plant Science and Ecology, 1(3), 88-92.

Islam, Shariful, Ali, A., Guswami, P., Sahibzada, S., Hossain, M., Ullah, M., Miah, F. and Prodhan, Sh.H. (2013) Assessment of genetic diversity among moderately drought tolerant landraces of rice using RAPD markers. J. BioSci. Biotech. 2(3), 207-213.

IWGSC 'The International Wheat Genome Sequencing Consortium' (2014) A chromosome-based draft sequence of the hexaploid bread wheat (Triticum aestivum) genome. Science. Doi: 10.1126/ science. 1251788 .

Kamal, A.H.M., Kim, K.H., Tsujimoto, H., Heo, H.Y., Park, C.S. and Woo, S.H. (2010) Abiotic stress responsive proteins of wheat grain determined using proteomics technique. Aust. J. Crop Sci. 4(3), 196-208

Kanawapee, N., Jirawat, S. and Pranee, S. (2011) Genetic diversity analysis of rice cultivars (Oryza sativa L.) differing in salinity tolerance based on
RAPD and SSR markers. Electronic Journal of Biotechnology, ISSN: 0717-3458 http://www. ejbiotechnology.info DOI: 10.2225/vol14-issue6fulltext-4

Karam, M.A., Abd-Elgawad, Magda E. and Ali, R.M. (2016) Differential gene expression of saltstressed Peganum harmala L. Journal of Genetic Engineering and Biotechnology, 14, 319-326.

Khalili, M. Reza, N. and Said, Y. (2018) Protein pattern analysis in tolerant and susceptible wheat cultivars under salinity stress conditions. Acta Agriculturae Slovenica, 111(3), 545-558.

Laemmili, U.K. (1970) Cleavage of structural proteins during the assembly of the head of bacteriophage T4. Nature, 227, 680-685.

Maleki, M., Naghavi, M.R., Alizadeh, H., Poostini, K. and Abd Mishani, C. (2014) Comparison of protein changes in the leaves of two bread wheat cultivars with different sensitivity under salt stress. Annual Research \& Review in Biology, 4(11), 1784-1797.

Manifesto, M.M., Schlatter, A.R., Hopp, H.E., Suárez, E.Y. and Dubcovsky, J. (2001) Evaluation of genetic diversity in wheat germplasm using molecular markers. Crop Sci. 41, 682-690.

Michel, B. and Kaufmann, M. (1973) The osmotic potential of polyethylene glycol 6000. Plant Physiol. 51, 914-916.

Mondini, L., Noorani, A. and Pagnotta, M.A. (2009) Assessing plant genetic diversity by molecular tools. Diversity, 1, 19-35.

Moradpour, K., Najaphy, A., Mansoorifar, S. and Mostafaie, A. (2014) Evaluation of leaf protein pattern in wheat genotypes under drought stress. Int. J. Adv. Biol. Biom. Res. 2(3), 840-846.

O"zlem Ates and So"nmezog, Begu"m Terzi (2018) Characterization of some bread wheat genotypes using molecular markers for drought tolerance. Physiology and Molecular Biology of Plants, 24, 159-166.

Pachauri, V., Taneja, N., Vikram, P., Singh, N.K. and Singh, S. (2013) Molecular and morphological characterisation of Indian farmers rice varieties (Oryza sativa L.). AJCS, 7, 923-932. 
Parchin, R.A., Najaphy, A., Mohebodini, M.Sh.M., Vaseghi, A., Sohrabi-Babahadi, F. and Mostafaie, A. (2014) Comparing protein pattern and drought tolerance indicators as screening techniques for drought tolerance common wheat genotypes. International Journal of Plant, Animal and Environmental Sciences, 4(2), 251-285.

Piyusha, S. and Naveen, K. (2018) SSR molecular markers are efficient tools for finding genetic diversity in bread wheat. International Journal of Current Microbiology and Applied Sciences, Special Issue-7, 1098-1105.

Porebski, S., Bailey, L.G. and Baum, B.R. (1997) Modification of a CTAB DNA extraction protocol for plants containing high polysaccharide and polyphenol components. Plant Molecular Biology Reporter, 15, 8-15.

Powell, W., Morgante, M., Andre, C. and Rafalski, A. (1996) The comparison of RFLP, RAPD, AFLP and SSR (Microsatellite) markers for germplasm analysis. Mol. Breed. 2, 225-238.

Preety, P., Mano, J., Vijay, K. and Anil, K. (2010) Comparative evaluation of genetic diversity using RAPD, SSR and cytochrome P450 gene based markers with respect to calcium content in finger millet (Eleusine coracana L. Gaertn.). Journal of Genetics, 89(2), 121-133.

Rani, C., Bishnoi, S., Kumar, B. and Datta, S. (2007) Changes in protein profile under sodium chloride and boron toxicity stress in seedlings of two cultivars. Indian J. Plant Physiol. 12(1), 13-17.

Razavizadeh, R. (2015) Protein pattern of canola (Brassica napus L.) changes in response to salt and salicylic acid in vitro. Biological Lett. 52(1-2), 1936.

Sewelam, N., Kazan, K. and Schenk, P.M. (2016) Global plant stress signaling: reactive oxygen species at the cross-road. Front Plant Sci. 7, 187.

Shah, S.M., Naveed, S.A. and Arif, M. (2013) Genetic diversity in Basmati and non- Basmati rice varieties based on microsatellite markers. Pak. J. Bot. 45, 423-431.

Sharbatkhari, M., Galeshi, S. and Shahbazi, M. (2013) Assessment of agro-physiological traits for salt tolerance in drought-tolerant wheat genotypes.
International Journal of Plant Production, 7 (3), 437-453.

Shavrukov, Yu. (2013) Salt stress or salt shock: Which genes ar we studying. J. Exp. Bot. 64(1), 119-127. https://doi.org/10.1093/jxb/ers316

Shikazono, N., Suzuki, C., Kitamura, S. and Watanabe, H. (2005) Analysis of mutations induced by carbon ions in Arabidopsis thaliana. J. Exp. Bot. 56, $587-$ 596.

Terletskaya, N., Zobova, N. and Elena, S. (2017) Growth and photosynthetic reactions of different species of wheat seedlings under drought and salt stress. Periodicum Biologorum, 11(9 1), 37-45.

Tomar, R.S.S., Tiwari, S., Vinod, Naik B.K., Chand, S. and Deshmukh, R., et al. (2016) Molecular and morpho-agronomical characterization of root architecture at seedling and reproductive stages for drought tolerance in wheat. PLOS ONE, 11(6), e0156528. Doi:10.1371/journal.pone.0156528.

Trivedi, D. and Patel, I. (2016) Effect of brassinosteroids on protein profiling of salinity susceptible and resistance cultivars of groundnut under salinity stress. European Journal of Biotechnology and Bioscience, 4(8), 38-46.

Ullah, I., Akhtar, N., Mehmood, N.I. and Noor, M. (2014) Effect of mannitol of two wheat cultivars. The Journal of Animal and Plant Sciences, 24(4), 1264-1251.

Varshney, R., Chabane, K., Hendre, P. and Graner, A. (2007) Comparative assessment of EST-SSR, ESTSNP and AFLP markers for evaluation of genetic diversity and conservation of genetic resources using wild, cultivated and Elite Barleys. Plant Sci. 173, 638-649.

Wattier, R., Engel, C., Saumitou-Laprade, P. and Valero, M. (1998) Short allele dominance as a source of heterozygote deficiency at microsatellite loci: Experimental evidence at the dinucleotide locus Gv1CT in Gracilaria gracilis (Rhodophyta). Molecular Ecology, 7, 1569-1573.

Williams, J., Kubelik, A.R and Tingey, S. (1990) DNA polmorphisms amplified by arbitrary primers are useful as genetic markers. Nucleic Acids Res. 18, 6531- 65305 . 
Wu, B., Munkhtuya, Y., Li, J., Hu, Y., Zhang, Q. and Zhang, Z. (2018) Comparative transcriptional profiling and physiological responses of two contrasting oat genotypes under salt stress.
Scientific Reports, 8, 16248. DOI: 10.1038/ s41598-018-34505-5

(Received 17/ 4/2019;

accepted 29/5 /2019)

\title{
التعبير الجيني والاختلافات الجزيئية في اثنين من التراكيب الوراثية للقمح تحت إجهاد \\ الملوحة والجفاف \\ منال حسن عيد \\ قسم النبات الزر اعى ـ كلية الزر اعة ـ جامعة قناة السويس ـ الاسماعيلية ـ مصر.
}

\begin{abstract}
اجريت هذه الدر اسة لتوضيح بعض النقاط البارزة حول الفرق بين صنفين من القمح مثتاقضين فى المقاومة فيما

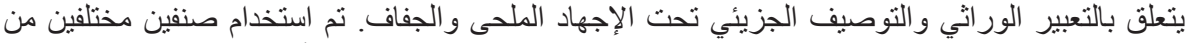

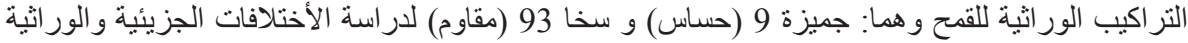

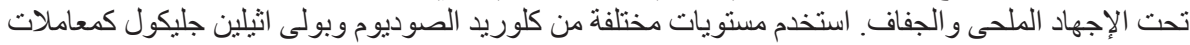

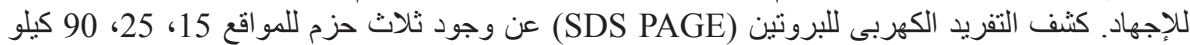

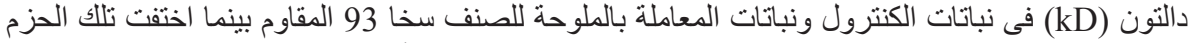

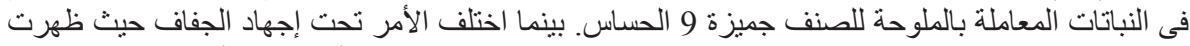

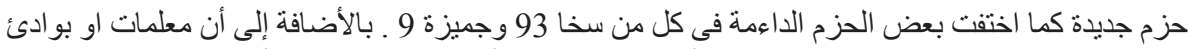

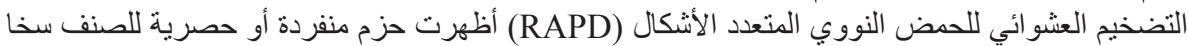

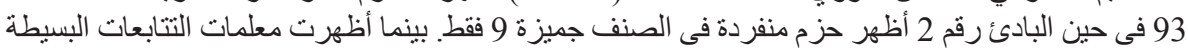

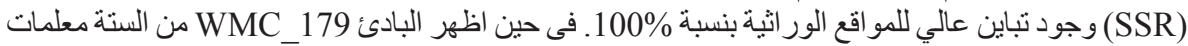

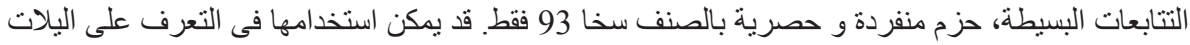

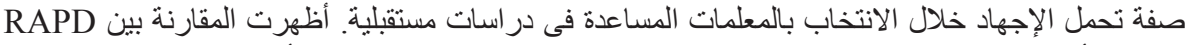

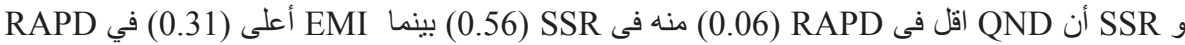
عنه في SSR (0.23). تعتبر النتائج ذات قيمة ومفيدة لتحديد الخصائص الور اثية و الجزيئية للأصناف الو اثية المختلفة المقاومة.
\end{abstract}

